\title{
Open repair for thoracoabdominal aortic aneurysms precipitated by chronic aortic dissection
}

\author{
Jonathan C. Hong ${ }^{1,2,3}$, Joseph S. Coselli $i^{1,2,3}$ \\ 'Division of Cardiothoracic Surgery, Michael E. DeBakey Department of Surgery, Baylor College of Medicine, Houston, TX 77030, \\ USA. \\ ${ }^{2}$ Department of Cardiovascular Surgery, Texas Heart Institute, Houston, TX 77030, USA. \\ ${ }^{3}$ Department of Cardiovascular Surgery, CHI St. Luke's-Baylor St. Luke's Medical Center, Houston, TX 77030, USA.
}

Correspondence to: Dr. Joseph S. Coselli, Division of Cardiothoracic Surgery, Michael E. DeBakey Department of Surgery, One Baylor Plaza, BCM 390, Houston, TX 77030, USA. E-mail: jcoselli@bcm.edu

How to cite this article: Hong JC, Coselli JS. Open repair for thoracoabdominal aortic aneurysms precipitated by chronic aortic dissection. Vessel Plus 2022;6:4. https://dx.doi.org/10.20517/2574-1209.2021.88

Received: 17 Jun 2021 First Decision: 14 Jul 2021 Revised: 20 Jul 2021 Accepted: 30 Jul 2021 Published: 6 Jan 2022

Academic Editors: Christopher Lau, Alexander D. Verin Copy Editor: Yue-Yue Zhang Production Editor: Yue-Yue Zhang

\begin{abstract}
Chronic dissection of the thoracoabdominal aorta may require surgical repair for aneurysm, malperfusion, or rupture. Endovascular repair is made difficult by a noncompliant dissection septum, visceral vessels arising from different lumens, and the common use of diseased aortic landing zones. Thus, open repair remains the gold standard in terms of favorable outcomes and durability. During thoracoabdominal aortic repair, we use a multimodal strategy to prevent spinal cord and visceral or renal artery ischemia; key modalities include cerebrospinal fluid drainage, left heart bypass with and without visceral protection, cold renal protection, and aggressive reimplantation of intercostal or lumbar arteries. Patients with chronic dissection require lifelong surveillance, as there is a significant risk for subsequent intervention on unrepaired aortic segments.
\end{abstract}

Keywords: Thoracoabdominal aorta, open surgery, chronic aortic dissection, type B aortic dissection, aortic aneurysm

\section{INTRODUCTION}

Aortic dissection begins as a tear in the intima that leads to a separation of the layers of the media and the propagation of blood along a false lumen. Acute aortic dissection of the thoracoabdominal aorta is a complex condition that can be further complicated by rupture and organ malperfusion. After three months, 
aortic dissection is typically considered chronic and is susceptible to aneurysm formation induced by a pressurized false lumen and other factors; subsequently, although most patients with chronic aortic dissection are initially managed medically, surgical intervention may become necessary ${ }^{[1,2]}$.

In this manuscript, we describe the classification of aortic dissection, along with indications for repair, and highlight operative techniques for open repair of aneurysms related to chronic dissection of the thoracoabdominal aorta.

\section{Classification}

Aortic dissection is classified by the anatomical distribution and time from onset, which guide treatment strategy. The most commonly used anatomical classification systems include the Stanford classification, the DeBakey classification, and the Society of Thoracic Surgeons/Society of Vascular Surgery (STS/SVS) system [Figure 1].

The Stanford classification characterizes the dissection on the basis of its location: dissection involving the ascending aorta is defined as type $\mathrm{A}$, and dissection involving the descending thoracic or thoracoabdominal aorta only is defined as type $\mathrm{B}^{[3]}$. The DeBakey classification further characterizes an aortic dissection on the basis of its distal extent $t^{[4]}$ : DeBakey type I aortic dissection is extensive, involving both the ascending aorta and the descending thoracic or thoracoabdominal aorta, whereas type II is strictly limited to the ascending aorta; DeBakey type III dissection originates distal to the left subclavian artery and is further subdivided into type IIIA, which is limited to the descending thoracic aorta, and type IIIB, which extends below the diaphragm ${ }^{[4]}$.

The STS/SVS classification was designed to characterize dissections of the aortic arch better and is based on the location of the originating tear. The aorta is divided into several zones (0 to 9); a type B dissection has an entry tear originating in zones 1 to 9 (distal to the innominate artery). The entry tear and distal extent of dissection zones are denoted by a subscripted zone number. Thus, extensive aortic dissection limited to thoracoabdominal aorta would be described as type $\mathrm{B}_{3,9}{ }^{[5]}$. The STS/SVS system also classifies aortic dissection by the time from the initial insult: Hyperacute is defined as $<24 \mathrm{~h}$; acute, 1-14 days; subacute, 1590 days; and chronic, $>90$ days ${ }^{[5]}$.

Thoracoabdominal aortic aneurysms (TAAAs) are classified by the extent of repair, according to the E. Stanley Crawford classification system [Figure 2] ${ }^{[6]}$. A Crawford extent I TAAA involves the descending thoracic aorta to the suprarenal aorta. An extent II TAAA involves the descending thoracic aorta to the aortoiliac bifurcation. An extent III TAAA involves the distal descending thoracic aorta (T6 aorta) to the aortoiliac bifurcation. Finally, an extent IV TAAA involves the aorta from the diaphragm to the aortoiliac bifurcation.

\section{Acute aortic dissection}

The initial management for acute aortic dissection is anti-impulse therapy (e.g., beta-blockers) to limit hemodynamic stress on the aortic wall and minimize propagation of the dissection by reducing heart rate, blood pressure, and the velocity of left ventricular contraction ${ }^{[7]}$. Our hemodynamic targets are a heart rate $<$ 70 beats per minute and systolic blood pressure of 100-120 mmHg. If the patient continues to be hypertensive with adequate heart rate control, vasodilator therapy is indicated.

Acute DeBakey type I or type II aortic dissection is a surgical emergency and requires the replacement of the dissected ascending aorta. Arch replacement with an elephant trunk may be indicated when the aortic arch 

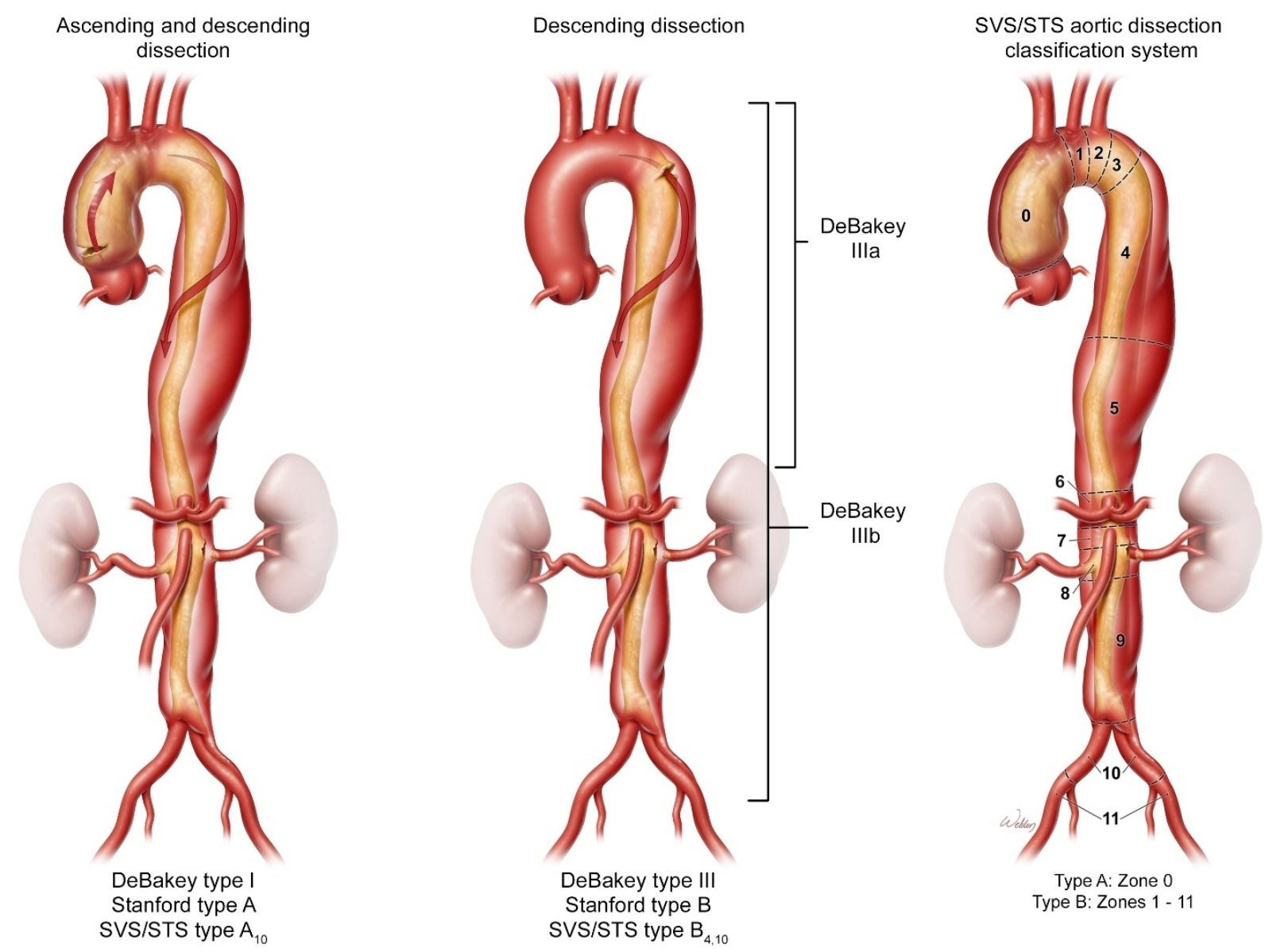

Figure 1. Traditionally, aortic dissection is classified on the basis of the involvement of the ascending aorta, the descending aorta, or both. For comparison, the corresponding traditional classifications for the DeBakey and Stanford systems are shown (left). Of note, the Stanford classification is limited in its ability to describe distal aortic involvement. The recent Society of Thoracic Surgeons and Society of Vascular Surgery classification system (right) is based on the origin of the intimal tear and uses zones 3 to 9 to describe the thoracoabdominal aorta. The figure is used with the permission of Baylor College of Medicine.

is aneurysmal, the primary intimal tear is in the arch or proximal descending aorta, there is evidence of malperfusion, or the patient is young and has a heritable thoracic aortic disease (e.g., Marfan syndrome). The elephant trunk is an extension of Dacron graft that may be free-floating or combined with a thoracic endovascular stent (frozen elephant trunk); it is placed within the true lumen of the proximal segment of the descending thoracic aorta and incorporated into the distal anastomosis of the arch replacement. The elephant trunk facilitates subsequent descending thoracic or thoracoabdominal aorta repair by moving the extent of aneurysm repair distally, thereby avoiding distal aortic arch manipulation through a left thoracoabdominal approach. Patients who have undergone surgery to repair DeBakey type I aortic dissection tend to develop subsequent aortic dilatation in the chronic phase that necessitates downstream aortic repair.

The management of uncomplicated, acute DeBakey type III dissection is controversial. This type of aortic dissection also is managed with anti-impulse therapy. However, the natural history of DeBakey type III aortic dissections that are managed medically is poor: $60 \%$ of patients develop aneurysmal rupture or dilatation requiring surgical repair within 5 years ${ }^{[8-11]}$, and the 5 -year survival rate of patients with untreated, chronic DeBakey type III dissection is only $60 \%-80 \%{ }^{[12-14]}$. Predictors of aneurysm formation after DeBakey 

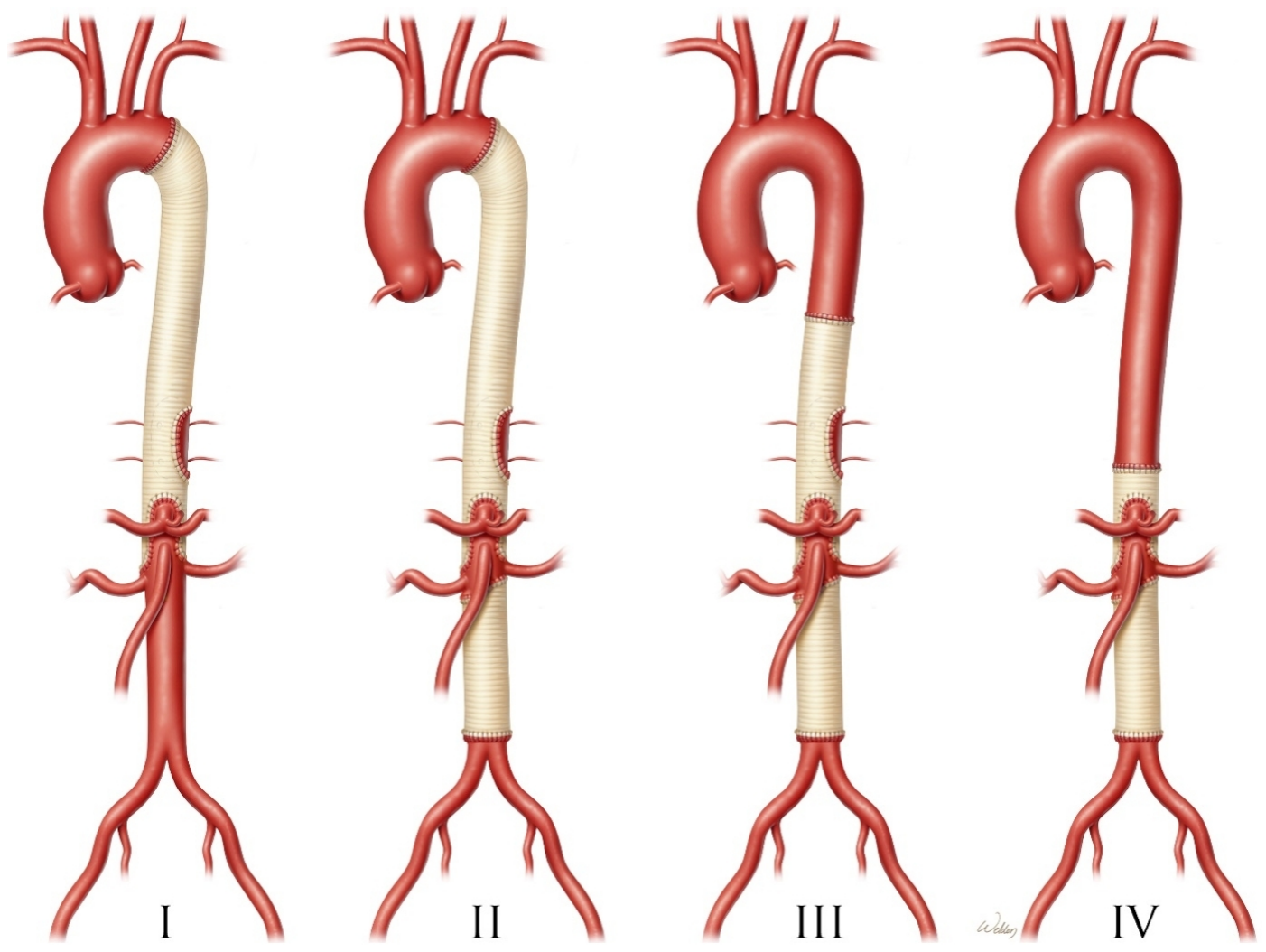

Figure 2. The Crawford classification scheme for describing the extent of thoracoabdominal aortic aneurysm (TAAA) repair. Extent II TAAA repairs have the greatest operative risk. The figure is used with the permission of Baylor College of Medicine.

type III dissection include uncontrolled hypertension, an initial aortic diameter $>4.0 \mathrm{~cm}$, an entry tear $>10$ $\mathrm{mm}$, partial thrombosis or continued patency of the distal false lumen, or a false lumen $>2.2 \mathrm{~cm}$ wide $^{[5,7,15-17]}$. Thus, there is a movement toward using thoracic endovascular aortic repair to induce aortic remodeling and obliteration of the false lumen to prevent late aortic complications ${ }^{[5]}$. If a DeBakey type III aortic dissection is complicated by malperfusion or rupture, our preferred strategy is an endovascular aortic repair to cover the primary entry tear, redirect flow to the true lumen, and depressurize the false lumen ${ }^{[5]}$. In rare circumstances, a complicated, acute DeBakey type III dissection may require open repair if endovascular repair is not technically feasible (e.g., if endovascular landing areas are inadequate) ${ }^{[18]}$.

\section{Chronic aortic dissection}

A chronically dissected aorta is susceptible to dilation and late aneurysm formation that necessitates repair [Figure 3]. The American College of Cardiology and American Heart Association guidelines for patients with aortic dissection of the thoracoabdominal aorta recommend open aortic repair when aortic diameter exceeds $5.5 \mathrm{~cm}$ (class I recommendation; level of evidence B); the diameter-based threshold is lowered in patients with rapid aortic growth $\left(>0.5 \mathrm{~cm} /\right.$ year) or heritable thoracic aortic disease ${ }^{[7]}$. Symptomatic aneurysms can signal impending rupture and should be urgently repaired, irrespective of aortic dimensions ${ }^{[7]}$. Other indications for repair include malperfusion syndromes or symptoms due to compression of surrounding structures ${ }^{[7]}$. Patients with aneurysms precipitated by chronic dissection are different from those with degenerative atherosclerotic aneurysms: they are typically younger, have fewer comorbidities, and are more likely to have heritable thoracic aortic disease ${ }^{[19]}$. 

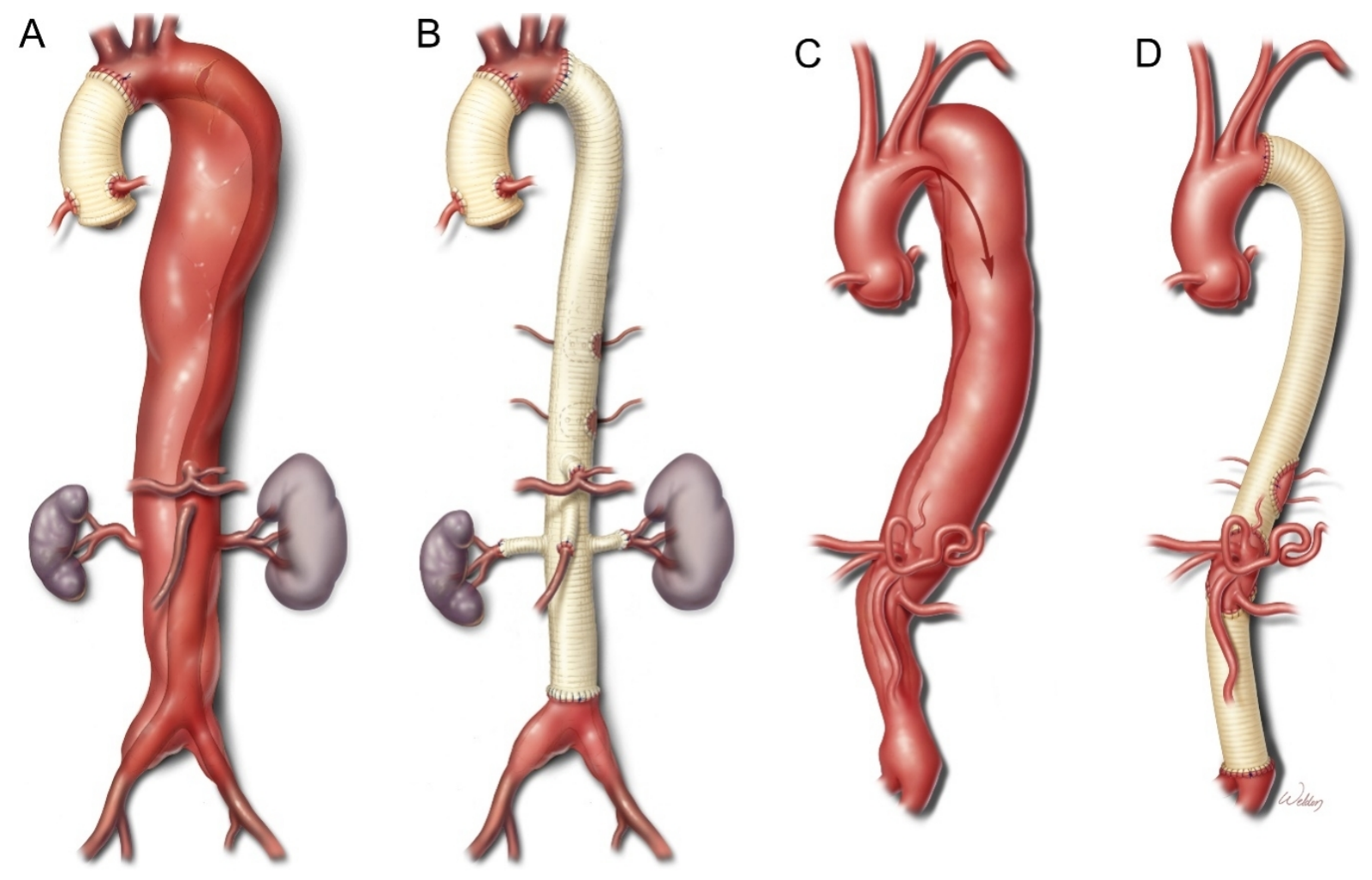

Figure 3. Open repair of thoracoabdominal aortic aneurysms (TAAAs) in patients with chronic aortic dissection. Distal aortic dilatation in survivors of DeBakey type I aortic dissection repair (A) may trigger subsequent downstream aortic repair (B). Likewise, patients undergoing medical management of DeBakey type III aortic dissection (C) may eventually need open TAAA repair (D). The figure is used with the permission of Baylor College of Medicine.

In general, open thoracoabdominal aortic repair of chronic dissection is preferred over experimental endovascular repair, a technique that is not yet widely available. In open repair, the thickened and stiff dissection septum is excised, and a common lumen is created by replacing it with an aortic graft. As a result, only the aneurysmal or symptomatic aortic segment is replaced, and a portion of residual chronic aortic dissection often remains.

Conversely, endovascular treatment of chronic dissection within the thoracoabdominal aorta is limited by the thickened and noncompliant dissecting septum, which prevents the elimination of false lumen blood flow even if the main entry tear is covered. Retrograde blood flow into the false lumen may persist at the distal landing zone, and the stent graft may introduce new entry tears ${ }^{[2,21]}$. Techniques to mitigate the influence of the noncompliant dissecting septum include: (1) using coils to embolize or plugs to obliterate the false lumen; or (2) creating a common aortic lumen by fenestration, stent-graft-assisted balloon aortic septal fracture, or provisional extension with a bare-metal stent to induce complete thromobosis ${ }^{[22-25]}$. Even so, the aortic diameter does not improve in $70 \%$ of patients with chronic dissection who undergo endovascular repair ${ }^{[26-28]}$. Open repair of aneurysms precipitated by chronic aortic dissection remains the gold standard.

\section{SURGICAL TECHNIQUE AT THE BAYLOR COLLEGE OF MEDICINE}

Our operative technique for open repair of Crawford extent II TAAAs precipitated by chronic aortic dissection involves the placement of a four-branched replacement graft. We prefer to use a prefabricated branched graft because (1) the visceral and renal arteries are often displaced in a chronic aortic dissection; 
(2) eliminating diseased aortic tissue mitigates the risk for the subsequent formation of an island patch aneurysm; and (3) reducing the anastomotic tension decreases the likelihood of late pseudoaneurysm formation.

\section{Preoperative imaging}

Meticulous analysis of preoperative imaging is the mainstay of TAAA repair. We look for calcification, dissection, and mural thrombus at potential aortic clamping and cannulation sites. Hypothermic circulatory arrest may be necessary if no suitable proximal aortic clamping site is available because of the aneurysm or a contained rupture. At our institution, we prefer a staged approach for treating patients with arch aneurysms (especially those related to chronic aortic dissection), in which we perform total aortic arch replacement by using an elephant trunk extension technique to set up the subsequent thoracoabdominal aneurysm repair. We rarely use hypothermic circulatory arrest during thoracoabdominal aortic repair, given the ensuing potential for coagulopathy and lung injury. The origins of important branching vessels, including the arch vessels and intercostal, lumbar, visceral, renal, and iliofemoral arteries, are assessed with respect to the true and false lumens. The spatial orientations of the renal and visceral arteries are considered in decisionmaking about the use of an island patch or individual branching grafts. Anatomic variations of the aorta, its branches, and the visceral organs also should be reviewed.

\section{Preparation, monitoring, and adjuncts for spinal cord protection}

Standard intravenous access is obtained by including a central line, a pulmonary artery catheter, and an arterial line in the right upper extremity for hemodynamic monitoring. A double-lumen endobronchial tube is used to facilitate single-lung ventilation. We have found that a bronchial blocker provides inferior lung isolation and results in a higher incidence of postoperative pulmonary contusion due to manual retraction of the lung. The patient's temperature is passively cooled to mild hypothermia $\left(32-33^{\circ} \mathrm{C}\right)$. Core temperature is measured in the nasopharynx. Cerebral oximetry is used to monitor cerebral perfusion throughout the procedure.

We use a multimodal strategy to prevent spinal cord, visceral artery, and renal artery injuries during TAAA repair. The mean arterial pressure (MAP) is kept at 70-90 $\mathrm{mmHg}$, measured from the right-sided upper extremity. In most cases, a left heart bypass (LHB) circuit with a cell saver for autotransfusion is used; however, a complete cardiopulmonary bypass circuit is needed for cases requiring hypothermic circulatory arrest $\left(18-20^{\circ} \mathrm{C}\right)$. In addition, cerebrospinal fluid (CSF) drainage is used for Crawford extent I and II TAAA repairs, extent III repairs when iliac artery replacement is anticipated, and extent IV repairs when previous descending thoracic aneurysm or extent I repairs are present. The CSF pressure is kept below $15 \mathrm{mmHg}$, and CSF is drained at a maximum rate of $10 \mathrm{~mL} / \mathrm{h}$ or $25 \mathrm{~mL}$ over $4 \mathrm{~h}$. Importantly, we use passive mild hypothermia, sequential cross-clamping, aggressive reimplantation of suitable intercostal or lumbar arteries, cold renal solution to protect the kidneys whenever possible, and isothermic blood from the LHB circuit to perfuse the celiac axis and superior mesenteric artery (SMA) $)^{[29-31]}$.

\section{Positioning, exposure, and left heart bypass}

The patient is placed in a modified right lateral decubitus position, with the upper body kept at 60 degrees and the hips kept at 30 degrees by using a suction-deflated beanbag [Figure 4]. The left arm is positioned in a freestyle swimming position at an angle above the shoulders. The operating table is gently flexed slightly superior to the anterior superior iliac spine. This position allows for exposure of the TAAA and the femoral arteries. A sigmoid skin incision is made beginning a finger breadth below the left scapula and coursing along the seventh rib, across the costal margin, to the left of the umbilicus. The ribs are counted in the plane deep to the serratus muscle along the spine, and the 6 th intercostal space is entered. A segment of the posterior rib may be removed to improve the exposure of the thoracic cavity. 

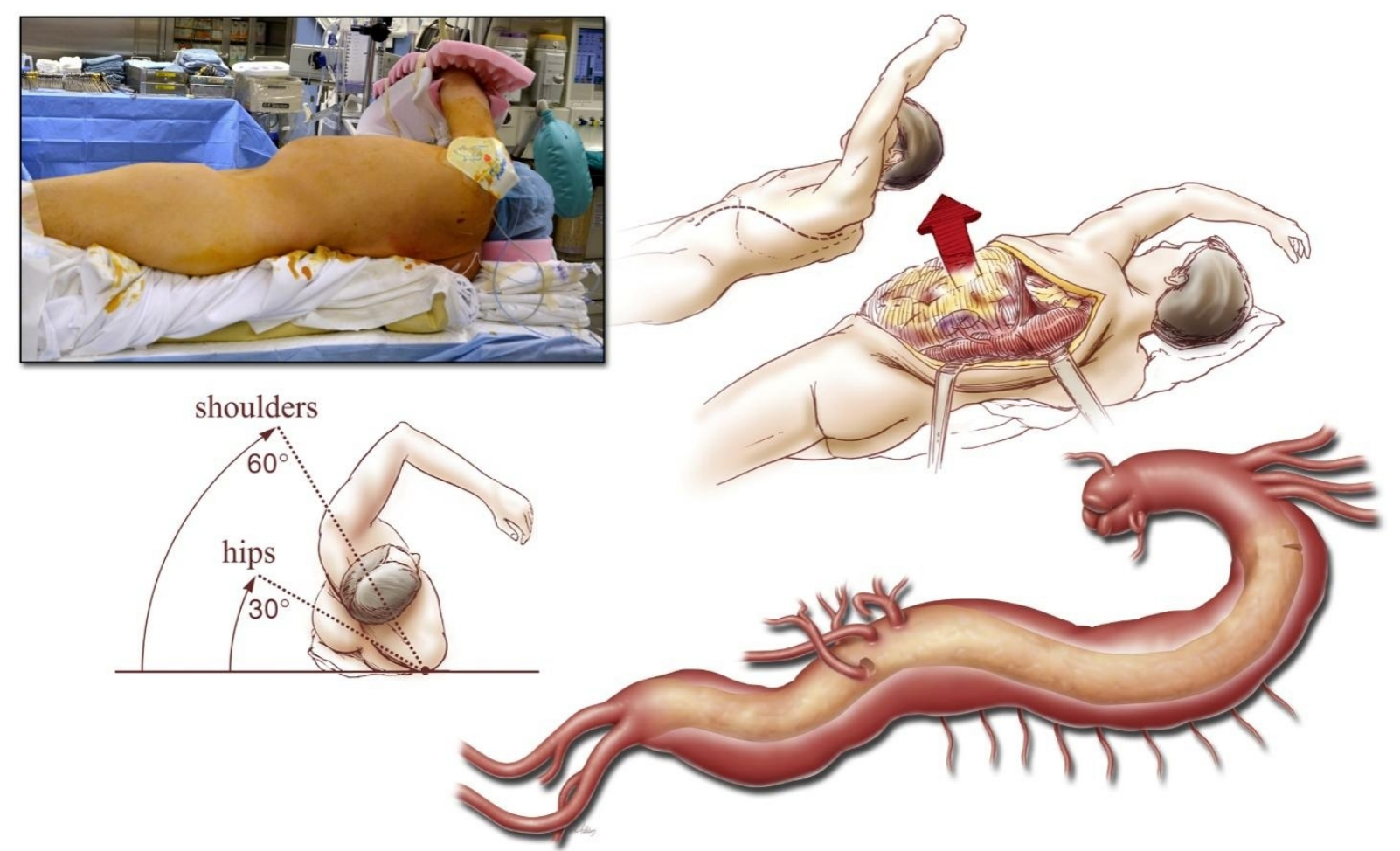

Figure 4. Positioning of the patient, incision, and exposure during repair of a Crawford extent II thoracoabdominal aortic aneurysm in a patient with DeBakey type III chronic aortic dissection. The figure is used with the permission of Baylor College of Medicine.

The diaphragm is divided circumferentially to preserve the neurovascular supply, leaving a 3 to 4 - $\mathrm{cm}$ rim of tissue from the left costal margin to the aortic hiatus. Taking care to avoid injury to the visceral organs, we cautiously open the peritoneum. Left medial visceral rotation is carried out by entering the plane along the line of Toldt. The left renal artery is identified and used as an anatomical landmark. The esophagus is located by palpating the nasogastric tube, and the left ureter is retracted medially with the viscera. Meticulous hemostasis is maintained during this dissection to prevent blood loss, impaired oxygen delivery, and coagulopathy. The proximal aorta is circumferentially freed, while the left recurrent laryngeal nerve is protected.

Adhesions from a previous DeBakey type I aortic dissection repair can interfere with preparing the proximal aorta for a cross-clamp. Placing an elephant trunk graft extension during the previous proximal aortic repair simplifies subsequent TAAA repair ${ }^{[32]}$. If the proximal repair during the index DeBakey type I aortic dissection included only the ascending aorta and hemiarch, a redo sternotomy and total arch replacement with an elephant trunk extension may be performed before the TAAA repair because an aortic arch aneurysm would be difficult to replace through a left thoracoabdominal exposure. Epiaortic ultrasound is helpful for locating the free-floating elephant trunk graft within the proximal portion of the descending thoracic aorta.

Left heart bypass to provide isothermic, self-oxygenated blood perfusion is facilitated by inserting a drainage cannula in the left inferior pulmonary vein and a return cannula in the distal aorta or femoral artery [Figure 5]. A careful review of preoperative imaging aids the selection of an ideal cannulation site, one that is free of thrombus and within the true lumen. However, multiple entry tears are common in the dissecting septum, and perfusion is typically maintained even if the false lumen is cannulated. Epiaortic ultrasound 


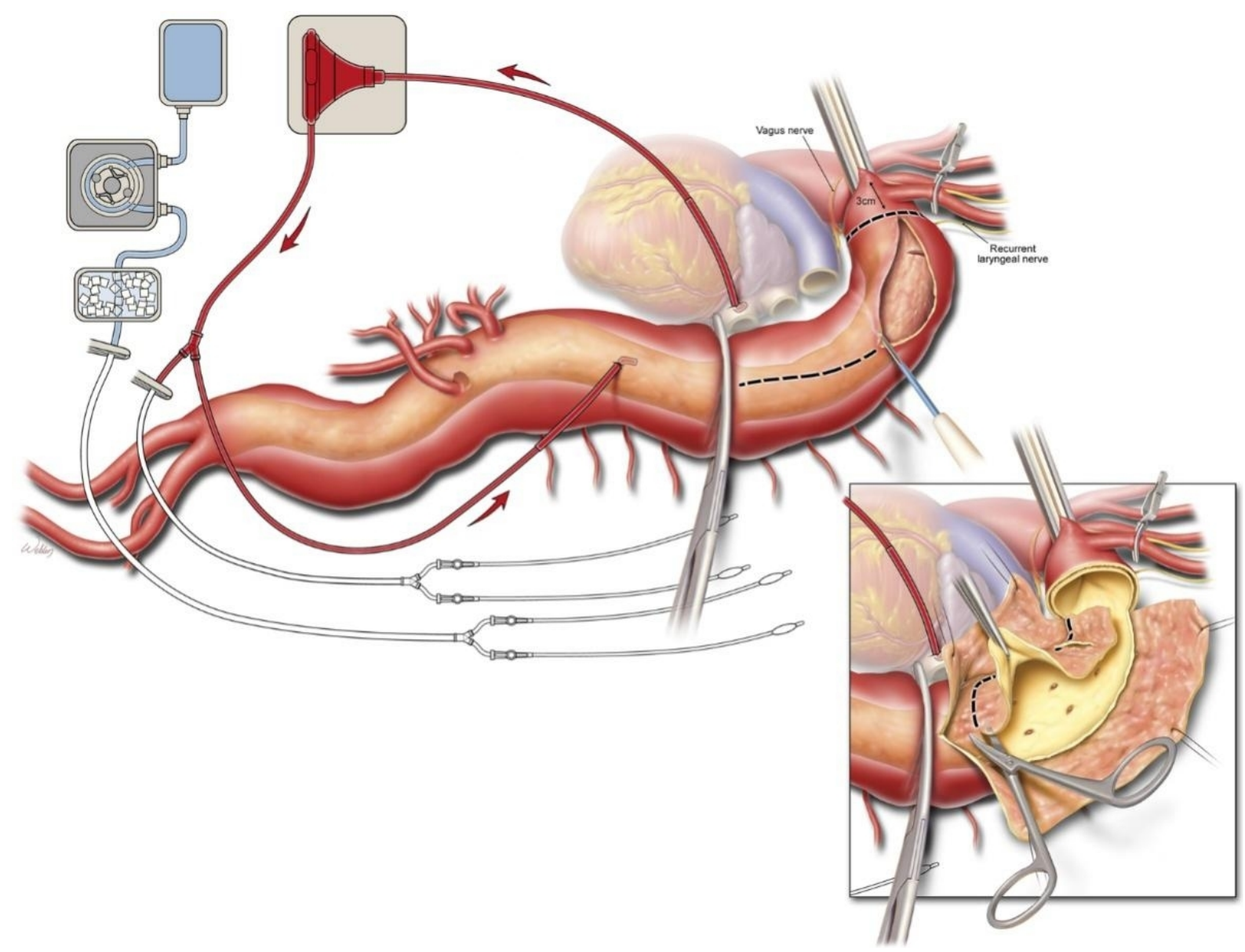

Figure 5. Initiation of left heart bypass with return and drainage cannulation sites, placement of aortic clamps (including a bulldog clamp across the left subclavian artery, if disease necessitates a more proximal aortic clamp site), and opening of the proximal portion of the descending thoracic aorta. In repairs involving chronic aortic dissection, the dividing septum is removed (inset). The figure is used with the permission of Baylor College of Medicine.

may also aid in identifying a distal aortic cannulation site in the true lumen. Heparin is administered (1.5 $\mathrm{mg} / \mathrm{kg}$ ) to achieve an activated clotting time $>280 \mathrm{~s}$ before LHB initiation at a flow rate of $3.5 \mathrm{~L} / \mathrm{min}$ once the aortic cross-clamp is applied.

\section{Proximal anastomosis}

A straight, padded aortic cross-clamp is applied, distal to the left subclavian artery whenever possible; it is commonly placed proximal to the left subclavian artery in patients with chronic aortic dissection because the pattern of aortic dilatation often involves the distal arch. If a cross-clamp is placed proximal to the left subclavian artery, then a stiff bulldog clamp is applied across the left subclavian artery [Figure 6]. If an elephant trunk graft is present, the distal aspect of the graft is identified by using epiaortic ultrasound, and a vascular clamp is applied across the aorta and elephant trunk. A Crafoord clamp is applied across the aorta at the distal aortic clamp site; most typically, this is at the T6-T7 vertebral level to preserve flow where the artery of Adamkiewicz commonly arises (T7-L2) from the LHB. The isolated aortic segment is checked to determine if it is depressurized by gently milking the blood. The LHB flow rate is increased to $3.5 \mathrm{~L} / \mathrm{min}$, and a MAP of 70-90 mmHg is maintained. To protect the brain, cerebral oximetry is monitored to ensure that blood flow to the left common carotid is not compromised. 


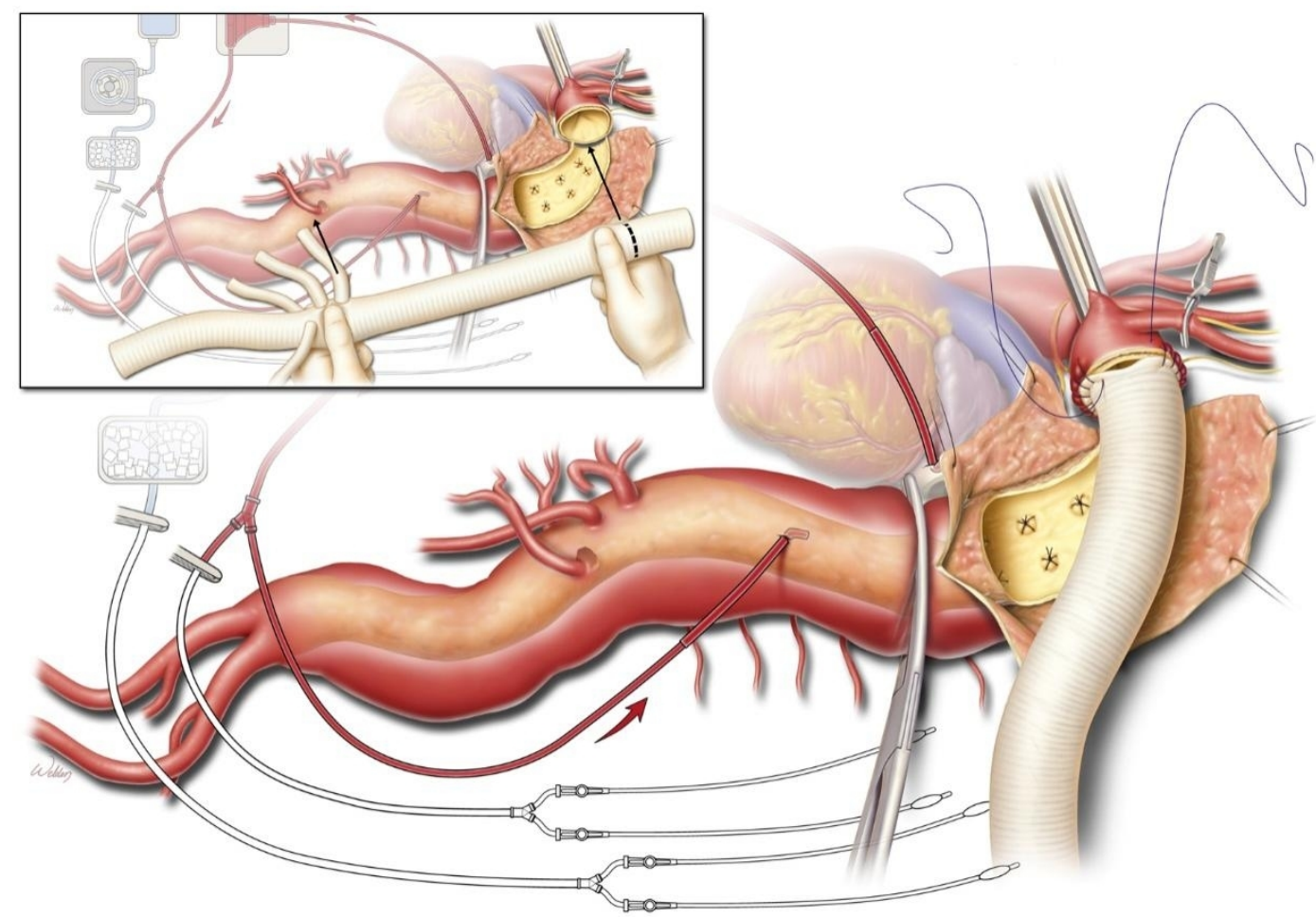

Figure 6. A 4-branched aortic replacement graft is sized to length to prepare for the proximal anastomosis (inset). In this segment, the intercostal arteries feeding the spinal cord are ligated to prevent steal from back-bleeding. Beginning with the difficult-to-rotate posterior portion, we suture the proximal anastomosis transluminally; care is taken to preserve the left recurrent laryngeal nerve. The figure is used with the permission of Baylor College of Medicine.

The aorta is opened longitudinally, and the aortic edges are retracted with silk stay sutures. The chronic dissection membrane is excised, recreating a single lumen. Briskly back-bleeding intercostal arteries are ligated with figure-of-eight sutures to improve visualization, minimize hemorrhage, and prevent shunting of blood from the spinal cord. In instances of hypothermic circulatory arrest, fenestration is carried out proximally. The aorta is trimmed for the proximal anastomosis, leaving a rim of approximately $3 \mathrm{~cm}$ to facilitate sewing. The back wall of the aorta is dissected away from the esophagus to avoid including esophageal tissue in the anastomosis, which could result in the late formation of an aortoesophageal fistula. The distance from the proximal anastomosis to the visceral branches is estimated by gently stretching the branched graft and trimming it to an approximate length. We typically use a 24 to 28 -mm gelatinimpregnated Dacron graft that is soaked in rifampin.

We begin the anastomosis at the posterolateral corner, continuing medially while ensuring that all layers of the aorta are included. A 3-0 polypropylene suture is used in a continuous fashion; however, a finer suture is often used in patients with heritable thoracic aortic disorders. When an elephant trunk is present, a graft-tograft anastomosis is performed. In cases involving a previous frozen elephant trunk repair, one or more rows of the metal struts may need to be removed before the stented portion of the device is sewn to the Dacron graft [Figure 7]. When the aortic arch is aneurysmal or an upstream aortic repair may be needed, a reverse elephant trunk may be used to simplify the subsequent proximal aortic repair. A reverse elephant trunk entails invaginating an 8 -cm portion of the Dacron graft, with the folded edge of the invaginated graft anastomosed to the aorta end-to-end with a continuous polypropylene suture ${ }^{[33]}$. 

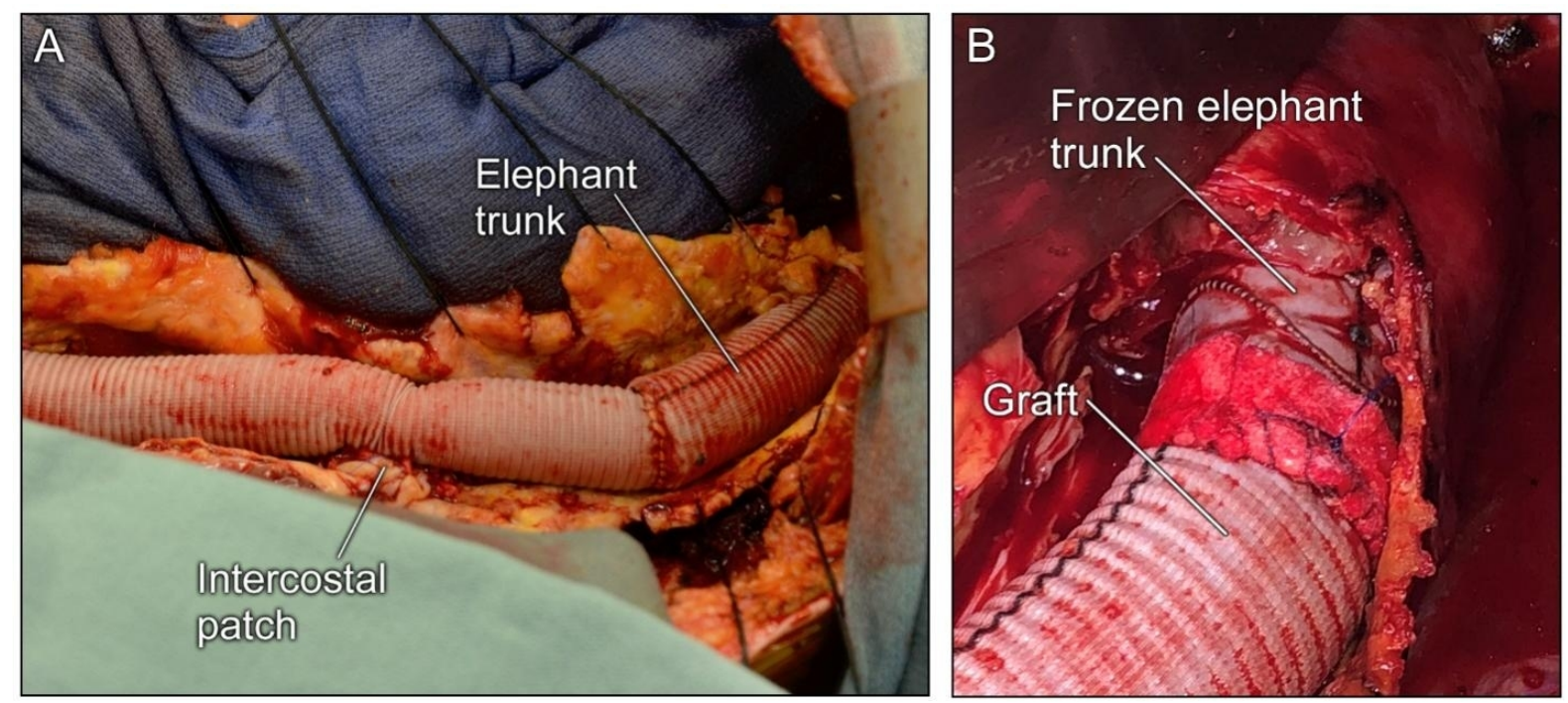

Figure 7. As indicated, the proximal anastomosis may be performed as completion of previous elephant trunk (A) and frozen elephant trunk (B) repairs. The graft-to-graft anastomosis is readily performed and aids hemostasis. If needed, a strip of felt can provide additional support to secure the anastomosis. The figure is used with the permission of Baylor College of Medicine.

After the primary suture line is completed, the graft is carefully examined for gaps, overlapping sutures, or tears in the aorta. Felt-pledgeted mattress sutures are applied to ensure a secure anastomosis, given that blood pressure targets are higher in the postoperative period. The cross-clamp initially placed proximal to the left subclavian artery is then moved onto the graft to reestablish flow to the left subclavian and vertebral arteries.

\section{Visceral and renal perfusion}

After the patient is weaned from LHB, the distal cannula and distal aortic cross-clamp are removed. This portion of the aorta is then opened longitudinally [Figure 8]. The dissecting septum and thrombus are removed, facilitating exposure of the entire aorta, including the intercostal, visceral, and lumbar branches. Briskly back-bleeding intercostal or lumbar arteries are oversewn to avoid steal. Selective visceral perfusion with isothermic, self-oxygenated blood is performed by using 9-French balloon-tipped catheters extending from a Y-branch of the LHB and inserted into the celiac axis and SMA at a flow rate of $300-400 \mathrm{~mL} / \mathrm{min}$. We protect the renal arteries with cold $\left(4^{\circ} \mathrm{C}\right)$ histidine-tryptophan-ketoglutarate perfusate $(300 \mathrm{~mL}$ every 6$12 \mathrm{~min}$ ) delivered by using 9-French balloon-tipped catheters extending from a separate cooling circuit; the patient's temperature is carefully monitored to avoid overcooling. Alternatively, the LHB circuit can be used to provide isothermic, self-oxygenated blood to all four branching arteries.

\section{Reimplantation of intercostal or lumbar arteries}

We identify 2 or 3 pairs of arteries feeding the spinal cord between T7 and L2 that are large and have minimal or no back-bleeding. These are to be used for reimplantation with an island patch or an 8-mm interposition Dacron graft. We typically use an island patch and a side-to-side anastomosis with 3-0 polypropylene sutures [Figure 9]. To reduce the risk for subsequent pseudoaneurysm formation, we minimize the inclusion of the native aorta in the patch. Felt-pledgeted mattress sutures are liberally used for reinforcement if the aortic tissue is fragile. The proximal aortic cross-clamp is then moved distally to the island patch to perfuse the spinal cord through the intercostal or lumbar arterial patch. 


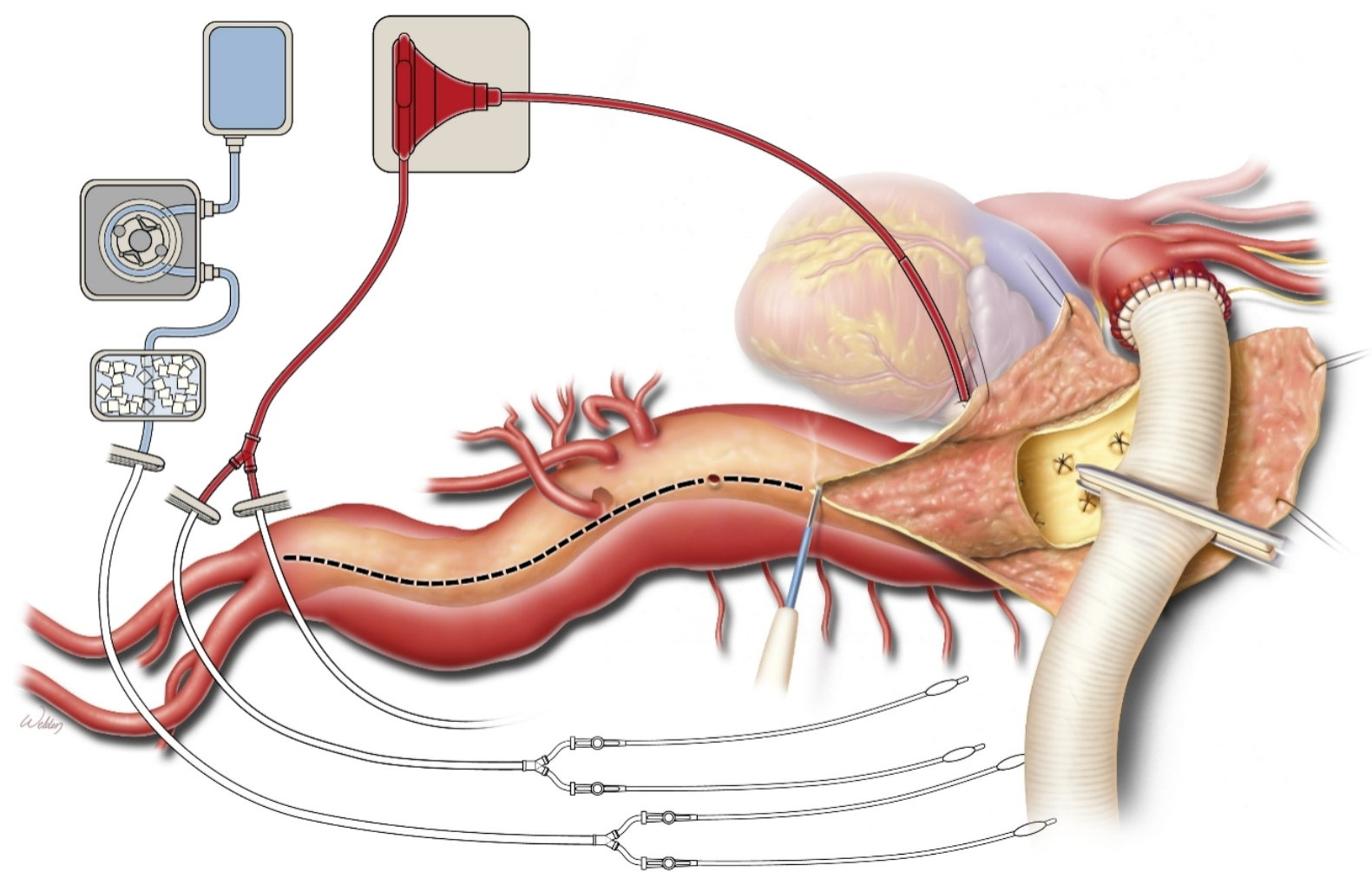

Figure 8. Extension of the aortic incision after the aortic cross-clamp is moved down onto the graft. The figure is used with the permission of Baylor College of Medicine.

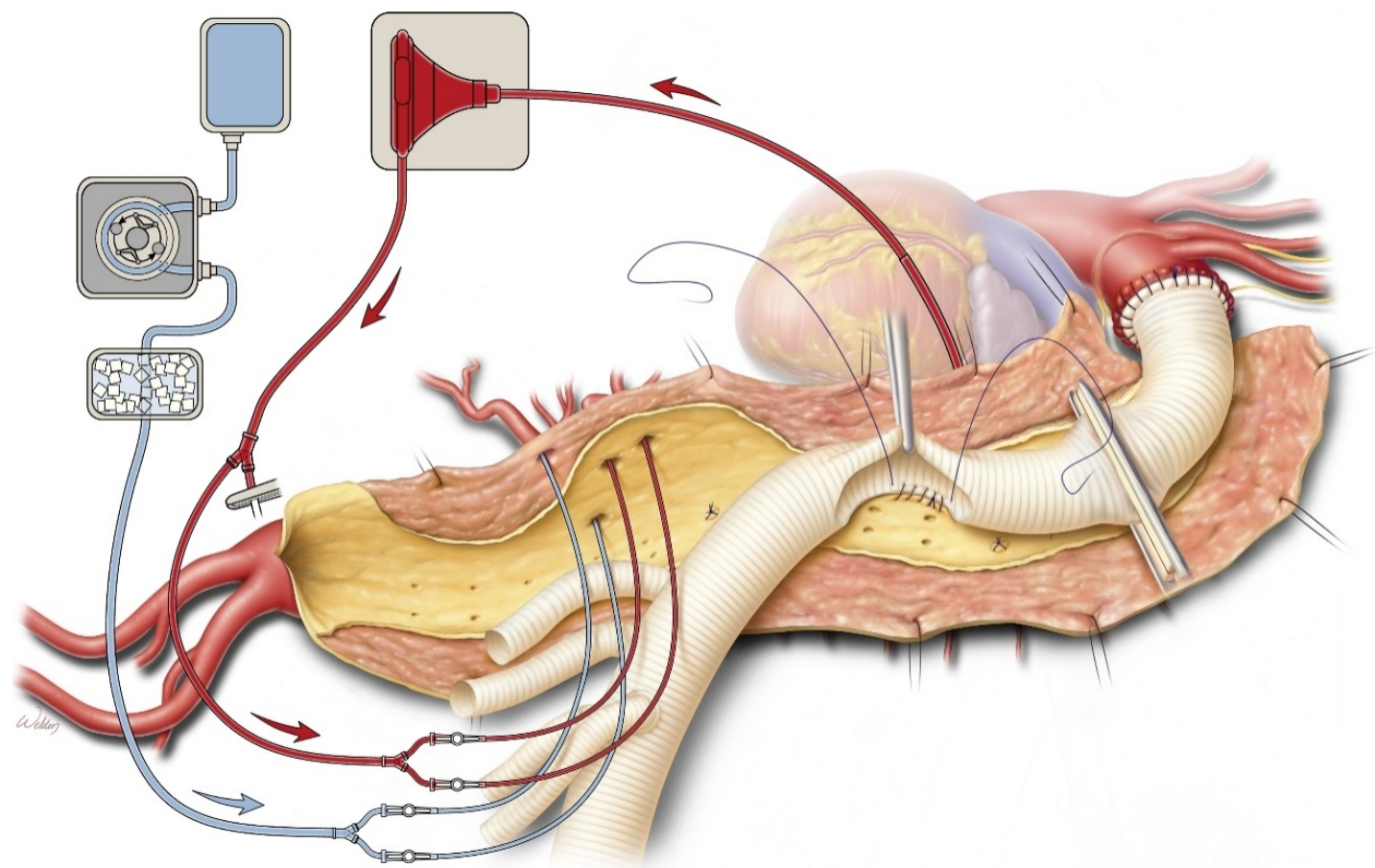

Figure 9. Initiation of visceral perfusion and the intercostal patch anastomosis. Isothermic blood is used to perfuse the celiac axis and the superior mesenteric artery; cold solution is used to perfuse the renal arteries. The figure is used with the permission of Baylor College of Medicine. 


\section{Distal anastomosis}

When a four-branched replacement graft is used, the distal anastomosis is performed before reattachment of the visceral and renal arteries to re-establish flow to the lower extremities while the visceral and renal organs continue to be perfused via the LHB and renal cooling circuit, respectively [Figure 10]. The distal aortic anastomosis is usually sewn at the level of the aortic bifurcation but can be anastomosed to the iliac or femoral arteries, using additional grafts as needed. If the chronic dissection extends distally, the septum is fenestrated to ensure downstream perfusion into both lumens. The aortic graft is cut to a suitable length to prevent kinking or tension, and a 3-0 polypropylene suture is used in a continuous fashion to complete the anastomosis. As before, felt-pledgeted mattress sutures are used to reinforce the anastomosis.

The patient is then placed in the Trendelenburg position, and a 19-gauge needle is used to create deairing holes in the Dacron graft. Individual clamps are placed on each of the four branches of the prefabricated graft. The aorta is deaired through one of the branches of the graft. The aortic cross-clamp is slowly removed to reestablish blood flow to the lower body. Anesthesia facilitates patient resuscitation to maintain MAP after cross-clamp removal; typically, the use of bicarbonate and vasopressors is necessary.

\section{Visceral and renal anastomosis with a four-branched graft}

The ostia of the celiac, SMA, and renal arteries are isolated on buttons of aortic tissue and are carefully inspected for extension of dissection as well as for calcium or stenosis related to the atherosclerotic process. Endarterectomy, decalcification, or direct stenting (usually with a 7-mm $\times 15-\mathrm{mm}$ balloon-expandable stent) may be required. If the dissection extends into the visceral arteries, fenestration may be necessary to ensure the perfusion of both lumens. The perfusion catheters are maintained to limit ischemic time. Because the right renal artery is most posterior, it is sewn first; we use a 4-0 or 5-0 polypropylene suture [Figure 11]. The anastomosis is deaired, and the clamp is released to reestablish perfusion. Then, the SMA and celiac axis anastomoses are carried out. We typically leave the SMA clamped during the celiac axis anastomosis to prevent back-bleeding through collateral arteries, which affects visualization. The left renal artery anastomosis is typically sewn last. The inferior mesenteric artery is usually oversewn, but reimplantation may be necessary if bilateral hypogastric artery occlusions, previous colectomy, or a diseased SMA are present.

\section{Hemostasis and closure}

In preparation for closure, the four-branched graft is inspected for malorientation, kinks, or twists. The femoral arteries, renal arteries, celiac axis, and SMA [Figure 12] are palpated for a distal pulse, and the kidneys are palpated for turgor. The bowel is visualized to confirm its perfusion. The spleen is inspected for any hematoma or laceration; any splenic injury that cannot be controlled with electrocautery or packing necessitates a splenectomy to avoid potential bleeding complications. The patient's temperature is passively rewarmed to $>34.5^{\circ} \mathrm{C}$. We confirm the position of the nasogastric tube before closure. An abdominal drain is placed in the retroperitoneal space. The left hemidiaphragm is reapproximated under tension by using a \#1 polypropylene continuous suture that is locked every three bites. Two chest tubes are placed, anterosuperiorly and posteroinferiorly. Absorbable pericostal sutures are placed in and around the ribs in a figure-of-eight, interrupted fashion with \#2 coated braided polyester sutures. Two \#7 steel wires are placed to secure the thoracotomy closure. The abdominal fascia is closed and tied to the diaphragmatic suture. Soft tissue is closed, and single-lung ventilation is discontinued.

\section{Postoperative care}

Critical care monitoring and volume resuscitation form the cornerstone of postoperative care in patients with a TAAA. The MAP is maintained at $80-100 \mathrm{mmHg}$, and the patient's neurological status is checked every hour, particularly the patient's leg strength. The patient's hemoglobin level is kept above $10 \mathrm{~g} / \mathrm{dL}$ to 


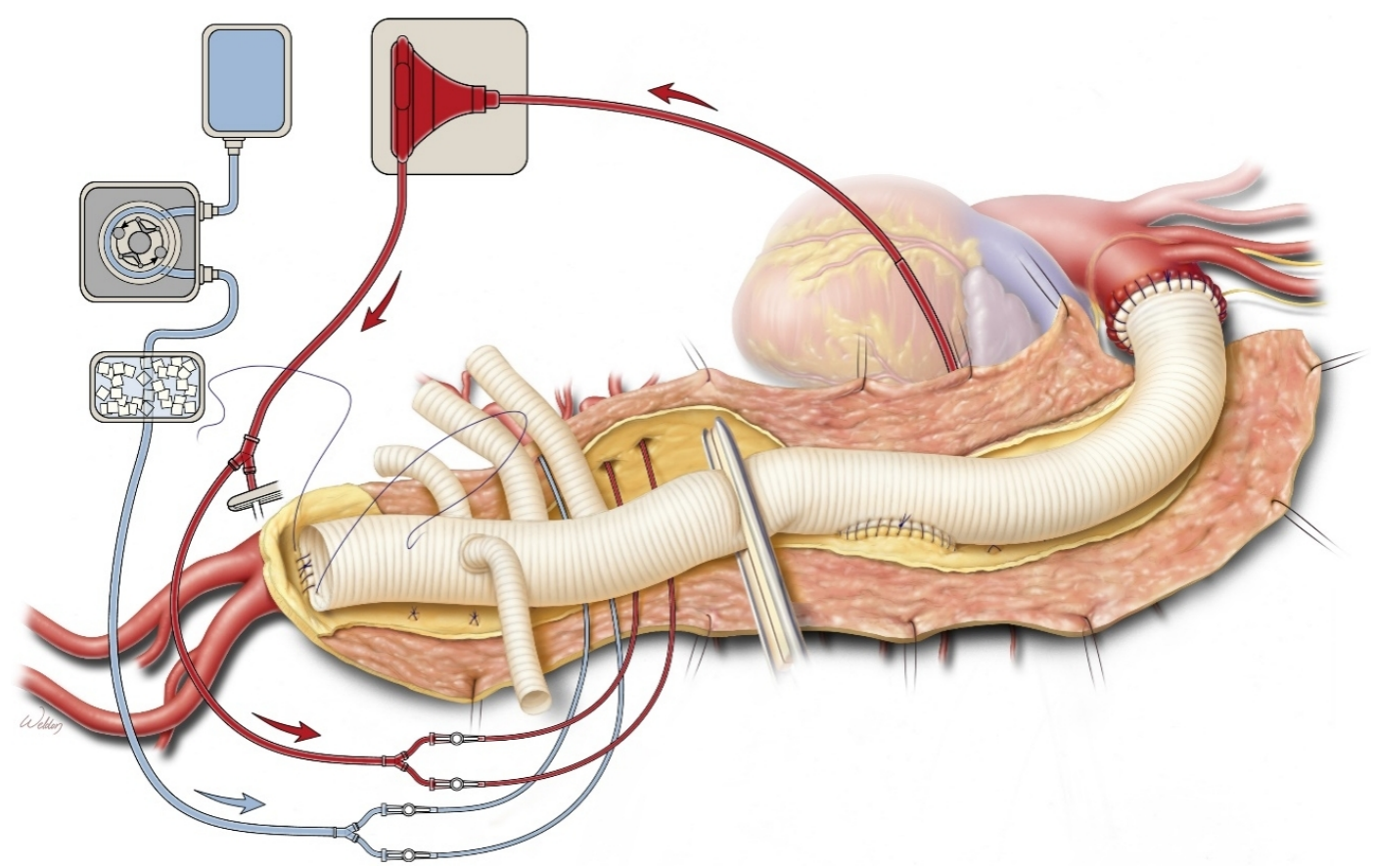

Figure 10. When a branched graft is used, the distal anastomosis is typically performed before the visceral arteries are reattached. Visceral perfusion is maintained while this anastomosis is performed. The figure is used with the permission of Baylor College of Medicine.

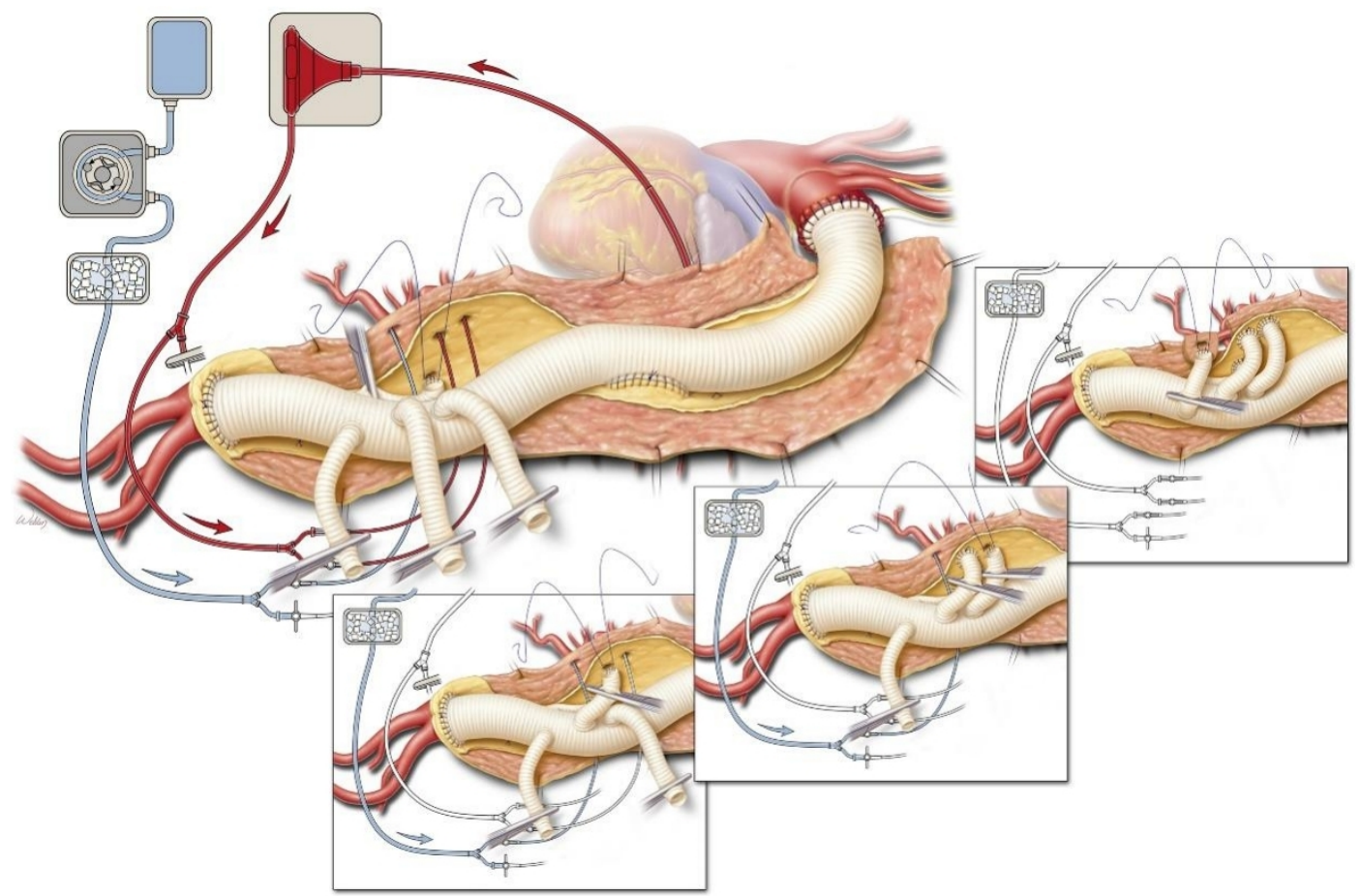

Figure 11. The right renal artery is typically the first to be anastomosed when a branched aortic graft is used. The superior mesenteric artery, celiac axis, and left renal artery will continue to be perfused until they are anastomosed (insets). The figure is used with the permission of Baylor College of Medicine. 


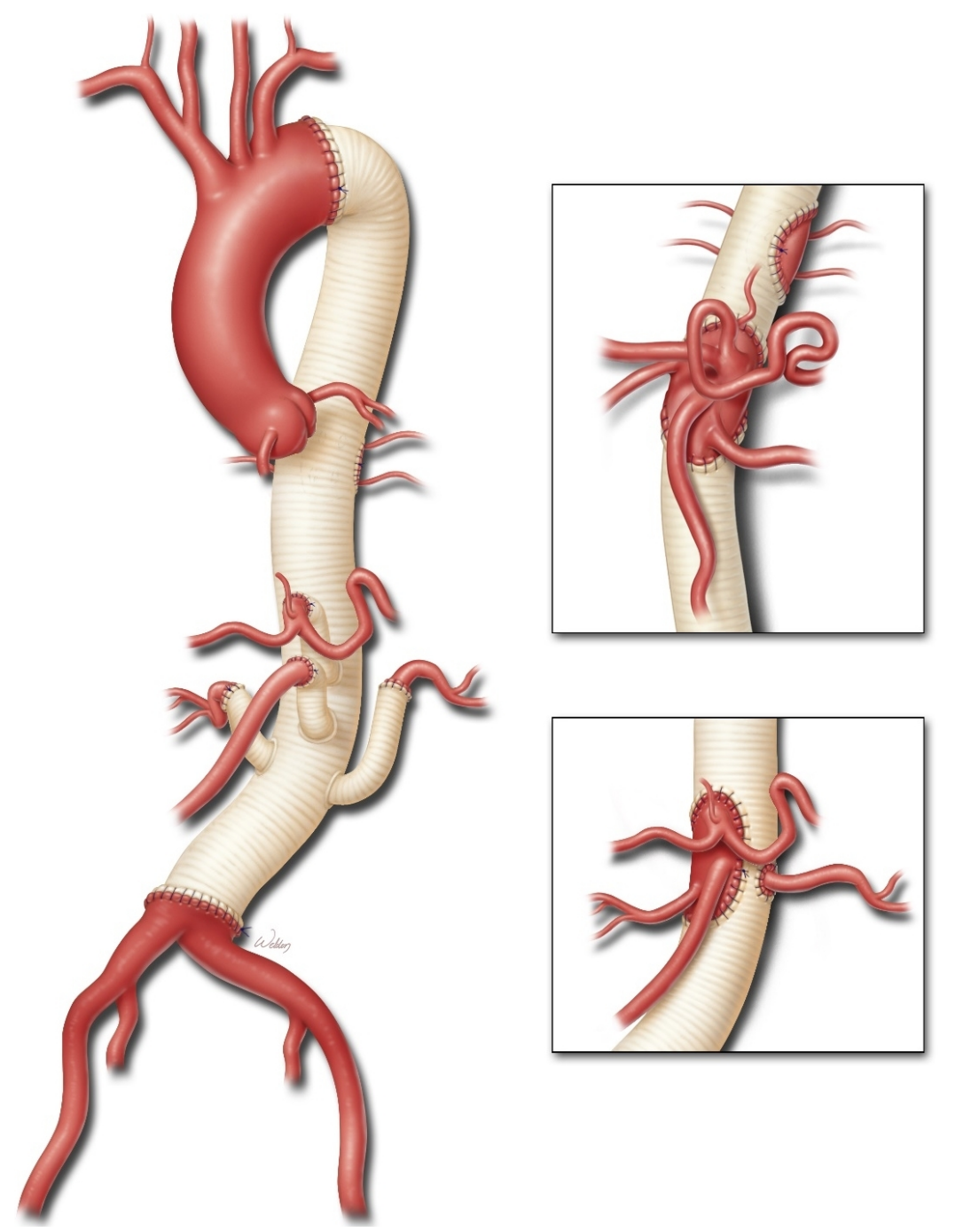

Figure 12. The completed repair of a DeBakey type III aortic dissection. A four-branched graft was used to aid Crawford extent II thoracoabdominal aortic aneurysm repair. Alternates to this approach include a single visceral patch that incorporates the celiac axis, superior mesenteric artery, and both renal arteries (upper inset) or a three-vessel patch that incorporates the celiac axis, superior mesenteric artery, and right renal arteries, with the left renal artery reattached as a button (lower inset). The figure is used with the permission of Baylor College of Medicine.

maximize oxygen delivery to end organs. The CSF drain is typically kept in place for $48-72 \mathrm{~h}$ postoperatively. The CSF drain is usually clamped for $8-12 \mathrm{~h}$ before removal to test for latent development of spinal ischemia. We typically extubate patients within $24 \mathrm{~h}$ and slowly start them on a solid diet on postoperative day 4. Typically, patients are discharged 7-10 days after open repair. Higher MAP goals are maintained for 4-6 weeks after surgery to prevent late neurological complications.

\section{CONCLUSION}

Chronic aortic dissections of the thoracoabdominal aorta are vulnerable to aneurysmal degeneration, rupture, malperfusion, or symptoms related to compression of surrounding structures related to aortic expansion. In studies of open repair of TAAAs precipitated by chronic dissection, the early mortality rate is $6 \%-8 \%$; the stroke rate is $1 \%-4 \%$; the incidence of paraplegia is $1 \%-3 \%$, and the incidence of renal failure requiring dialysis is $4 \%-5 \%^{[19,34-41]}$. However, open repair has favorable long-term durability. Estrera et al. ${ }^{[37]}$ 
reported $94 \%$ freedom from reoperation of the repaired distal aorta at 20 years, and Coselli et al ${ }^{[19]}$ reported 96\% freedom from reoperation of the repaired distal aorta at 7 years. In addition, Estrera et al. ${ }^{[37]}$ reported $82 \%$ freedom from progressive aortic repair at 20 years and $85 \%$ freedom at 7 years.

Open repair of thoracoabdominal aortic aneurysms precipitated by chronic dissection remains the gold standard, having exhibited favorable outcomes and durability. Nonetheless, patients with chronic dissection require a rigorous lifelong surveillance protocol, as there is a significant risk for subsequent intervention on any unrepaired aortic segments.

\section{DECLARATIONS}

\section{Acknowledgments}

The authors thank Scott A. Weldon, MA, CMI, FAMI, of the Michael E. DeBakey Department of Surgery at Baylor College of Medicine, for creating several of the illustrations. We thank Jeanie F. Woodruff, BS, ELS, of the Department of Scientific Publications at the Texas Heart Institute, and Susan Y. Green, MPH, of the Michael E. DeBakey Department of Surgery at Baylor College of Medicine, for providing editorial support. All images are used with permission of Baylor College of Medicine.

\section{Authors' contributions}

Made substantial contributions to the conception or design of the work, or the acquisition, analysis, or interpretation of data for the work: Hong JC, Coselli JS

Drafted the work or revised it critically for important intellectual content: Hong JC, Coselli JS

Gave final approval of the version to be published: Hong JC, Coselli JS

Agreed to be accountable for all aspects of the work, ensuring that questions related to the accuracy or integrity of any part of the work are appropriately investigated and resolved: Hong JC, Coselli JS

\section{Availability of data and materials}

Not applicable.

\section{Financial support and sponsorship}

Dr. Coselli's work is partly supported by the Cullen Foundation.

\section{Conflicts of interest}

Dr. Coselli consults for, receives royalties and a departmental educational grant from, and participates in clinical trials for Terumo Aortic; consults and participates in clinical trials for Medtronic, Inc., and W. L. Gore \& Associates; and serves as a co-investigator for CytoSorbents. Dr. Hong has no disclosures.

\section{Ethical approval and consent to participate}

Not applicable.

\section{Consent for publication}

Not applicable.

\section{Copyright}

(c) The Author(s) 2022.

\section{REFERENCES}

1. Oda T, Minatoya K, Sasaki H, et al. Surgical indication for chronic aortic dissection in descending thoracic and thoracoabdominal aorta. Circ Cardiovasc Interv 2017;10:e004292. DOI PubMed

2. Zafar MA, Chen JF, Wu J, et al; Yale Aortic Institute Natural History Investigators. Natural history of descending thoracic and thoracoabdominal aortic aneurysms. J Thorac Cardiovasc Surg 2021;161:498-511.e1. DOI PubMed 
3. Daily PO, Trueblood HW, Stinson EB, Wuerflein RD, Shumway NE. Management of acute aortic dissections. Ann Thorac Surg 1970;10:237-47. DOI PubMed

4. DeBakey ME, Henly WS, Cooley DA, Morris GC, Crawford ES, Beall AC. Surgical management of dissecting aneurysms of the aorta. $J$ Thorac Cardiovasc Surg 1965;49:130-49. DOI PubMed

5. Lombardi JV, Hughes GC, Appoo JJ, et al. Society for Vascular Surgery (SVS) and Society of Thoracic Surgeons (STS) reporting standards for type B aortic dissections. J Vasc Surg 2020;71:723-47. DOI PubMed

6. Crawford ES. Thoraco-abdominal and abdominal aortic aneurysms involving renal, superior mesenteric, celiac arteries. Ann Surg 1974;179:763-72. DOI PubMed PMC

7. Hiratzka LF, Bakris GL, Beckman JA, et al; American College of Cardiology Foundation/American Heart Association Task Force on Practice Guidelines; American Association for Thoracic Surgery; American College of Radiology; American Stroke Association; Society of Cardiovascular Anesthesiologists; Society for Cardiovascular Angiography and Interventions; Society of Interventional Radiology; Society of Thoracic Surgeons; Society for Vascular Medicine. 2010 ACCF/AHA/AATS/ACR/ASA/SCA/SCAI/SIR/STS/SVM Guidelines for the diagnosis and management of patients with thoracic aortic disease. A Report of the American College of Cardiology Foundation/American Heart Association Task Force on Practice Guidelines, American Association for Thoracic Surgery, American College of Radiology, American Stroke Association, Society of Cardiovascular Anesthesiologists, Society for Cardiovascular Angiography and Interventions, Society of Interventional Radiology, Society of Thoracic Surgeons, and Society for Vascular Medicine. J Am Coll Cardiol 2010;55:e27-e129. DOI PubMed

8. Juvonen T, Ergin M, Galla JD, et al. Risk factors for rupture of chronic type B dissections. J Thorac Cardiovasc Surg 1999;117:77686. DOI PubMed

9. Schwartz SI, Durham C, Clouse WD, et al. Predictors of late aortic intervention in patients with medically treated type B aortic dissection. J Vasc Surg 2018;67:78-84. DOI PubMed

10. Durham CA, Cambria RP, Wang LJ, et al. The natural history of medically managed acute type B aortic dissection. J Vasc Surg 2015;61:1192-8. DOI PubMed

11. Tsai TT, Fattori R, Trimarchi S, et al; International Registry of Acute Aortic Dissection. Long-term survival in patients presenting with type B acute aortic dissection: insights from the International Registry of Acute Aortic Dissection. Circulation 2006;114:2226-31. DOI PubMed

12. Fattori R, Montgomery D, Lovato L, et al. Survival after endovascular therapy in patients with type B aortic dissection: a report from the International Registry of Acute Aortic Dissection (IRAD). JACC Cardiovasc Interv 2013;6:876-82. DOI PubMed

13. Glower DD, Fann JI, Speier RH, Morrison L, White WD, et al. Comparison of medical and surgical therapy for uncomplicated descending aortic dissection. Circulation 1990;82:IV39-46. PubMed

14. Umaña JP, Lai DT, Mitchell RS, et al. Is medical therapy still the optimal treatment strategy for patients with acute type B aortic dissections? J Thorac Cardiovasc Surg 2002;124:896-910. DOI PubMed

15. Nienaber CA, Kische S, Rousseau H, et al; INSTEAD-XL trial. Endovascular repair of type B aortic dissection: long-term results of the randomized investigation of stent grafts in aortic dissection trial. Circ Cardiovasc Interv 2013;6:407-16. DOI PubMed

16. Moulakakis KG, Mylonas SN, Dalainas I, Kakisis J, Kotsis T, Liapis CD. Management of complicated and uncomplicated acute type B dissection. A systematic review and meta-analysis. Ann Cardiothorac Surg 2014;3:234-46. DOI PubMed PMC

17. Thrumurthy SG, Karthikesalingam A, Patterson BO, et al. A systematic review of mid-term outcomes of thoracic endovascular repair (TEVAR) of chronic type B aortic dissection. Eur J Vasc Endovasc Surg 2011;42:632-47. DOI PubMed

18. Czerny M, Schmidli J, Adler S, et al; EACTS/ESVS scientific document group. Current options and recommendations for the treatment of thoracic aortic pathologies involving the aortic arch: an expert consensus document of the European Association for Cardio-Thoracic surgery (EACTS) and the European Society for Vascular Surgery (ESVS). Eur J Cardiothorac Surg 2019;55:133-62. DOI PubMed

19. Coselli JS, Green SY, Zarda S, et al. Outcomes of open distal aortic aneurysm repair in patients with chronic DeBakey type I dissection. J Thorac Cardiovasc Surg 2014;148:2986-93.e1. DOI PubMed

20. Hughes GC. Stent graft-induced new entry tear (SINE): intentional and NOT. J Thorac Cardiovasc Surg 2019;157:101-6.e3. DOI PubMed

21. Andersen ND, Keenan JE, Ganapathi AM, Gaca JG, McCann RL, Hughes GC. Current management and outcome of chronic type B aortic dissection: results with open and endovascular repair since the advent of thoracic endografting. Ann Cardiothorac Surg 2014;3:264-74. DOI PubMed PMC

22. Rohlffs F, Tsilimparis N, Fiorucci B, Heidemann F, Debus ES, Kölbel T. The candy-plug technique: technical aspects and early results of a new endovascular method for false lumen occlusion in chronic aortic dissection. J Endovasc Ther 2017;24:549-55. DOI PubMed

23. Kölbel T, Carpenter SW, Lohrenz C, Tsilimparis N, Larena-Avellaneda A, Debus ES. Addressing persistent false lumen flow in chronic aortic dissection: the knickerbocker technique. J Endovasc Ther 2014;21:117-22. DOI PubMed

24. Iwakoshi S, Watkins CA, Ogawa Y, et al. "Cheese Wire" fenestration of dissection intimal flap to facilitate thoracic endovascular aortic repair in chronic dissection. J Vasc Interv Radiol 2020;31:150-4.e2. DOI PubMed

25. Kazimierczak A, Rynio P, Jędrzejczak T, et al. Expanded Petticoat technique to promote the reduction of contrasted false lumen volume in patients with chronic type B aortic dissection. J Vasc Surg 2019;70:1782-91. DOI PubMed

26. Conway AM, Qato K, Mondry LR, Stoffels GJ, Giangola G, Carroccio A. Outcomes of thoracic endovascular aortic repair for chronic aortic dissections. J Vasc Surg 2018;67:1345-52. DOI PubMed

27. Sultan I, Siki MA, Bavaria JE, et al. Predicting distal aortic remodeling after endovascular repair for chronic DeBakey III aortic dissection. Ann Thorac Surg 2018;105:1691-6. DOI PubMed 
28. Rocha RV, Lindsay TF, Austin PC, et al. Outcomes after endovascular versus open thoracoabdominal aortic aneurysm repair: a population-based study. J Thorac Cardiovasc Surg 2021;161:516-27.e6. DOI PubMed

29. Coselli JS, Green SY, Price MD, et al. Spinal cord deficit after 1114 extent II open thoracoabdominal aortic aneurysm repairs. $J$ Thorac Cardiovasc Surg ;2019:1-13. DOI PubMed

30. Coselli JS, LeMaire SA. Left heart bypass reduces paraplegia rates after thoracoabdominal aortic aneurysm repair. Ann Thorac Surg 1999;67:1931-4. DOI PubMed

31. Coselli JS, LeMaire SA, Köksoy C, Schmittling ZC, Curling PE. Cerebrospinal fluid drainage reduces paraplegia after thoracoabdominal aortic aneurysm repair: results of a randomized clinical trial. J Vasc Surg 2002;35:631-9. DOI PubMed

32. LeMaire SA, Carter SA, Coselli JS. The elephant trunk technique for staged repair of complex aneurysms of the entire thoracic aorta. Ann Thorac Surg 2006;81:1561-9. DOI PubMed

33. Coselli JS, Krause HM, Green SY, et al. A 23-year experience with the reversed elephant trunk technique for staged repair of extensive thoracic aortic aneurysm. J Thorac Cardiovasc Surg 2020:S0022-5223(20)33140. DOI PubMed

34. Kouchoukos NT, Kulik A, Castner CF. Open thoracoabdominal aortic repair for chronic type B dissection. J Thorac Cardiovasc Surg 2015;149:S125-9. DOI PubMed

35. Preventza O, Price MD, Amarasekara HS, et al. Chronic Type I and Type III aortic dissections: a propensity analysis of outcomes after open distal repair. Eur J Cardiothorac Surg 2018;54:510-6. DOI PubMed

36. Conway AM, Sadek M, Lugo J, et al. Outcomes of open surgical repair for chronic type B aortic dissections. J Vasc Surg 2014;59:1217-23. DOI PubMed

37. Estrera AL, Jan A, Sandhu H, et al. Outcomes of open repair for chronic descending thoracic aortic dissection. Ann Thorac Surg 2015;99:786-93. DOI PubMed

38. Pujara AC, Roselli EE, Hernandez AV, et al. Open repair of chronic distal aortic dissection in the endovascular era: implications for disease management. J Thorac Cardiovasc Surg 2012;144:866-73. DOI PubMed

39. Fujikawa T, Yamamoto S, Sekine Y, et al. Operative results and clinical features of chronic Stanford type B aortic dissection: examination of 234 patients over 6 years. Eur J Vasc Endovasc Surg 2015;50:738-43. DOI PubMed

40. Alfonsi J, Murana G, Smeenk HG, et al. Open surgical repair of post-dissection thoraco-abdominal aortic aneurysms: early and late outcomes of a single-centre study involving over 200 patients. Eur J Cardiothorac Surg 2018;54:382-8. DOI PubMed

41. Tanaka A, Sandhu HK, Afifi RO, et al. Outcomes of open repairs of chronic distal aortic dissection anatomically amenable to endovascular repairs. J Thorac Cardiovasc Surg 2019;S0022-5223(19)32094-X. DOI PubMed 